\title{
Breast cancer subtype discordance: impact on post-recurrence survival and potential treatment options
}

\author{
Peter F. McAnena', Andrew McGuire', A. Ramli', C. Curran' ', C. Malone², R. McLaughlin², K. Barry², \\ James A.L. Brown ${ }^{1 *}$ and M. J. Kerin ${ }^{1}$
}

\begin{abstract}
Background: Recent studies have shown that breast cancer subtype can change from the primary tumour to the recurrence. Discordance between primary and recurrent breast cancer has implications for further treatment and ultimately prognosis. The aim of the study was to determine the rate of change between primary and recurrence of breast cancer and to assess the impact of these changes on survival and potential treatment options.

Methods: Patient demographics were collected on those who underwent surgery for breast cancer between 2001 and 2014 and had a recurrence with biopsy results and pathology scoring of both the primary and recurrence.

Results: One hundred thirty two consecutive patients were included. There were 31 (23.5\%) changes in subtype. Discordance occurred most frequently in luminal A breast cancer $(n=20)$, followed by triple negative $(n=4)$, luminal B $(n=3)$ and HER2 $(n=3)$. Patients who changed from luminal A to triple negative $(n=18)$ had a significantly worse post-recurrence survival $(p<0.05)$ with overall survival approaching significance $(p=0.064)$ compared to concordant luminal A cases $(n=46)$. Overall receptor discordance rates were: estrogen receptor $20.4 \%(n=27)$, progesterone receptor $37.7 \%(n=50)$ and HER2 3\% $(n=4)$. Loss of estrogen receptor and progesterone receptor was more common than gain (21 vs. $6(p=0.04)$ and 44 vs. 6 ( $p=0.01$ ) respectively). Nine patients $(6.8 \%)$ gained receptor status potentially impacting treatment options.
\end{abstract}

Conclusion: Discordance in subtype and receptor status occurs between primary and recurrent breast cancer, ultimately affecting survival and potentially impacting treatment options.

Keywords: Breast cancer, Subtype, Discordance, Post-recurrence survival, Triple negative

\section{Background}

Breast cancer is the second most common cancer worldwide and the most common cancer among women with an estimated 1.67 million women diagnosed annually, and the fifth leading cause of death from cancer overall [1]. Risk of recurrence and outcome in breast cancer have conventionally been stratified according to the tumour size, grade, nodal status and especially tumour subtype [2]. Breast cancer is a heterogeneous disease with 3 established immunohistochemical biomarkers: Estrogen Receptor (ER), progesterone receptor (PR) and

\footnotetext{
* Correspondence: james.brown@nuigalway.ie

'Discipline of Surgery, Lambe Institute for Translational Research, School of

Medicine, National University of Ireland Galway, Galway, Ireland

Full list of author information is available at the end of the article
}

HER2 (human epidermal growth factor 2) receptor. The presence or absence of these receptors defines the four distinct molecular subtypes of breast cancer- luminal A (ER/PR positive, HER2 negative), luminal B (ER and/or PR positive, HER2 positive), HER2 over-expressing (HER2 positive alone) and triple negative (negative for all 3 receptors) [3]. Each subtype exhibits distinct prognoses, rates of recurrence and different treatment strategies [4]. Following treatment, breast cancer recurrence can be classed as either loco-regional (LRR; confined to the ipsilateral breast/lymph nodes) or distant. Recurrence rates are influenced by the original breast cancer subtype, the specific therapy received and the response to the therapy [5]. Traditionally, recurrent tumours have been have been assumed to be biologically similar (the 
same subtype) to the primary tumour. Recent studies have demonstrated that hormonal and HER2 receptor status can change status between primary and recurrent breast cancer [6]. This can impact prognosis with loss of receptor status associated with a poorer prognosis $[7,8]$. A change in receptor status could potentially lead to a change in treatment options, as patients whose recurrent tumour becomes hormone positive could be candidates for hormonal therapy and similarly patients who become HER2 positive may benefit from receiving Trastuzumab $[9,10]$.

The aim of our study was to identify subtype change in recurrent breast cancer at our institution, to assess the impact of discordance on patient outcomes, and to identify any potential changes in treatment due to a subtype change and if in reality patients who changed subtype experienced a change in treatment strategy.

\section{Methods}

\section{Case selection}

Data was collected on patients who had a recurrence of breast cancer following surgery $+/$ - chemotherapy/hormonal therapy/radiotherapy at the Galway Hospitals group between 2001 and 2014. Loco-regional recurrence after surgery was defined as the appearance of tumour in the ipsilateral chest wall or axillary, internal mammary or supraclavicular lymph nodes while distant recurrence was defined as recurrence to distant organs, confirmed by pathologists report. Only patients who had clinical pathology scoring of receptor status of both the primary and recurrent cancer were included. Exclusion criteria included presentation with bilateral tumours, biopsy results that were incomplete, and pathologist report of the recurrence as a new primary tumour. PAS software was used to access pathology records with MOSAIQ software used to determine patient pathways and treatment.

\section{Pathology}

Analysis of all samples was performed at the Pathology Laboratory, University Hospital Galway independently by clinical pathologists. Samples were obtained following surgery and at recurrence, with sufficient slides taken to perform all necessary immunohistochemical and pathological analysis. Samples were reviewed by a minimum of two pathologists, with an initial assessment from at least one primary reporting pathologist and a subsequent review performed by a pathologist at a multi-disciplinary meeting. The ER and PR receptor status were determined independently by clinical pathologists using immunohistochemistry [11] as per ASCO guidelines (ALLRED score $>2$ or more than $1 \%$ stain positive). The HER2 receptor status was identified by Herceptest [12] as part of the routine clinical evaluation, with a score of $3+$ considered positive. Any +2 inconclusive results were confirmed using FISH testing [13] as per ASCO guidelines, with a HER2/CEP17 ratio greater than two considered amplified.

\section{Statistical analysis}

Data analysis was performed using SPSS Version 21 (SPSS Inc., Chicago, IL). Overall survival and postrecurrence survival were estimated using the KaplanMeier product limit method. The log rank was used to determine any statistically significant differences in survival between the indicated groups. Comparative analyses were performed between groups using Chisquared and T-tests. Statistical significance was accepted for $p<0.05$.

\section{Ethics, consent and permissions}

This study was conducted in accordance with the granted National University of Ireland Galway and University College Hospital Galway ethical approval. All patients had histologically confirmed breast cancer and all relevant clinic-pathological and demographic data were obtained from a prospectively maintained breast cancer database. This study used retrospectively collected, de-identified data, and no patients were involved.

\section{Results}

\section{Patient demographics}

One hundred thirty two patients were included. Mean age at diagnosis was 53.3 year (range $21-84$ ). 58 patients (44\%) had a loco-regional recurrence while 74 (56\%) had a distant recurrence (Table 1). Bone was the most common distant recurrence $(n=27)$, followed by liver $(n=22)$ and lung $(n=16)$ (Table 2$) .49$ patients $(37.2 \%)$ had breast-conserving surgery while 83 (62.8\%) underwent mastectomy. 58 patients (44\%) received neoadjuvant chemotherapy prior to their primary surgery, with a mean time of 181 days $(\mathrm{SD} \pm 89.7$ ) between diagnosis and surgery in this group. Mean time from diagnosis of primary disease to diagnosis of recurrence was 38.7 months (range 2-144 months) (Table 1). Mean overall survival (OS) was 60.1 months (SD \pm 38.2 months) while mean post-recurrence survival (PRS) was 20.8 months (SD \pm 21.1 months). The majority of patients in our cohort were stage 2 or stage $3(41.6 \%$ and $29.5 \%$ respectively), grade 2 or $3(40.1 \%$ and $52.3 \%$ respectively (Table 3 ).

\section{Receptor discordance \& survival}

Rates of single receptor discordance for ER, PR and HER2 receptors were $20.4 \%(n=27), 37.8 \%(n=50)$, and $3 \%(n=4)$ respectively (Table 4$)$.Overall survival (OS) was comparable between the ER discordant group $(n=27)$ and the ER concordant group ( $n=105)$, (60.2 vs. 59.3 months), while post-recurrence survival (PRS) was shorter in the 
Table 1 Cohort description

\begin{tabular}{|c|c|}
\hline Patient Details & Total $(n=132)$ \\
\hline Age at diagnosis: mean years (SD \pm ) & $53.3(\mathrm{SD} \pm 13.6)$ \\
\hline Time to recurrence: mean months (SD \pm ) & $38.7(S D \pm 27.7)$ \\
\hline \multicolumn{2}{|l|}{ Recurrence location } \\
\hline Loco-regional & $58(44 \%)$ \\
\hline Distal & $74(56 \%)$ \\
\hline \multicolumn{2}{|l|}{ Neoadjuvant Chemo Rx } \\
\hline Received & $58(44 \%)$ \\
\hline Did not receive & $74(56 \%)$ \\
\hline \multicolumn{2}{|l|}{ Surgery } \\
\hline Mastectomy & $83(62.8 \%)$ \\
\hline Wide local excision & $49(37.2 \%)$ \\
\hline \multicolumn{2}{|l|}{ Survival: Months } \\
\hline Overall: mean (SD \pm ) & $60(38.3)$ \\
\hline Post-recurrence survival: mean (SD \pm ) & $20.7(21.1)$ \\
\hline \multicolumn{2}{|l|}{ Original subtype } \\
\hline Luminal A & $67(50.7 \%)$ \\
\hline Luminal B & $10(7.5 \%)$ \\
\hline HER2 & $15(11.3 \%)$ \\
\hline Triple negative & $40(30.5 \%)$ \\
\hline \multicolumn{2}{|l|}{ Recurrence subtype } \\
\hline Luminal A & $54(40.9 \%)$ \\
\hline Luminal B & $9(6.9 \%)$ \\
\hline HER2 & $16(12.1 \%)$ \\
\hline Triple negative & $53(40.1 \%)$ \\
\hline
\end{tabular}

discordant group, but this was not statistically significant (21.6 vs. 17.4 months, $p=0.36$ ). There was no statistically significant difference in OS or PRS between the PR discordant $(\mathrm{n}=50)$ and concordant $(n=82)$ groups (OS 67.1 vs. 55.7 months, $p=0.096$, PRS 23.3 vs. 19.1 months, $p=0.096)$. In terms of HER2 receptor, there was a significant difference between the discordant $(n=4)$ and

Table 2 Distant recurrence location \& change in subtype

\begin{tabular}{lll}
\hline $\begin{array}{l}\text { Distant recurrences } \\
(n=74)\end{array}$ & $\mathrm{N}(\%)$ & $\begin{array}{l}\text { Proportion that } \\
\text { changed subtype }\end{array}$ \\
\hline Bone & $27(36 \%)$ & $4(14 \%)$ \\
Liver & $22(30 \%)$ & $5(23 \%)$ \\
Lung & $16(22 \%)$ & $4(25 \%)$ \\
Lymph node distant & $6(8 \%)$ & $1(17 \%)$ \\
Brain & $2(3 \%)$ & 0 \\
Adrenal & $1(1.5 \%)$ & 0 \\
\hline
\end{tabular}

Table 3 Primary tumour features

\begin{tabular}{|c|c|c|}
\hline Tumor details & $\mathrm{n}$ & (\%) \\
\hline \multicolumn{3}{|l|}{ Stage } \\
\hline । & 15 & $11.3 \%$ \\
\hline$\|$ & 55 & $41.6 \%$ \\
\hline III A/B & 39 & $29.5 \%$ \\
\hline III C & 23 & $17.4 \%$ \\
\hline \multicolumn{3}{|l|}{ Grade } \\
\hline 1 & 10 & $7.6 \%$ \\
\hline 2 & 53 & $40.1 \%$ \\
\hline 3 & 69 & $52.3 \%$ \\
\hline \multicolumn{3}{|l|}{$\mathrm{T}$} \\
\hline 1 & 37 & $28 \%$ \\
\hline 2 & 58 & $43 \%$ \\
\hline 3 & 34 & $25.7 \%$ \\
\hline 4 & 3 & $2.3 \%$ \\
\hline \multicolumn{3}{|l|}{ N } \\
\hline 0 & 34 & $25.8 \%$ \\
\hline 1 & 46 & $34.8 \%$ \\
\hline 2 & 29 & $21 \%$ \\
\hline 3 & 23 & $14.4 \%$ \\
\hline
\end{tabular}

Table 4 Receptor discordance

\begin{tabular}{ll}
\hline ER & \\
Concordant & $105(79.6 \%)$ \\
Discordant & $27(20.4 \%)$ \\
Gain & $6(4.5 \%)$ \\
Loss & $21(15.9 \%)$ \\
PR & \\
Concordant & \\
Discordant & $82(62.1 \%)$ \\
Gain & $50(37.8 \%)$ \\
Loss & $6(4.5 \%)$ \\
HER2 & $44(33.2 \%)$ \\
Concordant & \\
Discordant & $128(97 \%)$ \\
Gain & $4(3 \%)$ \\
Loss & $2(1.5 \%)$ \\
Subtype & $2(1.5 \%)$ \\
Concordant & $\mathrm{N}(\%)$ \\
Discordant & $101(76.5 \%)$ \\
\hline
\end{tabular}


concordant $(n=128)$ groups in OS and PRS (OS 157 vs. 57 months, $p<0.05$; PRS 60.7 vs. 19.5 months, $p<0.05$ ). However, the very low numbers in the discordant group limit the value of this result. There was a statistically significant loss compared to gain of both ER and PR receptor status (ER loss $n=21(15.9 \%)$ vs. gain $n=6(4.5 \%)$, $p=0.04 ; \mathrm{PR} n=44(33.2 \%)$ vs. $\mathrm{n}=6$ (4.5\%), $p=0.01)$. Of the four HER2 receptor discordant cases, two gained and two lost receptor status, however these numbers are too low to draw statistical significance.

\section{Subtype discordance \& survival}

There were 31 patients (23.5\%) who had a different subtype on recurrence, 17 were loco-regional recurrences and 14 were distant (Fig. 1). The group who changed subtype $(n=31)$ had a longer mean time to recurrence compared to the concordant group $(n=101)$ (44.9 vs. 36.9 months, $p=0.16$ ) (Table 5). Recurrence location, type of surgery received and neo-adjuvant
Table $\mathbf{5}$ Impact of subtype change and gain in receptor status on survival

\begin{tabular}{llll}
\hline $\begin{array}{l}\text { Patient } \\
\text { Details }\end{array}$ & Total & $\begin{array}{l}\text { Change } \\
\text { subtype } \\
(\mathrm{n}=31)\end{array}$ & $\begin{array}{l}\text { Gain } \\
\text { of Receptor } \\
(n=132)\end{array}$ \\
\hline $\begin{array}{llll}23.5 \% \\
\text { Survival: Months }\end{array}$ & $\mathrm{N}(\%)$ & $\mathrm{N}(\%)$ & $\mathrm{N}(\%)$ \\
$\begin{array}{l}\text { Overall: mean (SD } \pm) \\
\begin{array}{l}\text { Post-recurrence survival: } \\
\text { mean (SD } \pm)\end{array}\end{array}$ & $60(38.3)$ & $64.9(40.3)$ & $76.9(56.3)$ \\
\hline
\end{tabular}

therapy were not associated with subtype change $(p=0.3$, $p=0.83, p=0.674$ respectively) (Additional file 1: Table $\mathrm{S} 1)$. A change from luminal A to triple negative $(n=18)$ subtype resulted in poorer 10 year OS versus the concordant luminal A group $(n=46)$ which approached statistical significance (46.8 vs. 67 months, $p=0.064$ ) (Fig. 2A). Importantly, there was a statistically significant shorter 5 year PRS between the two groups, (8.6 vs. 22.5 months,
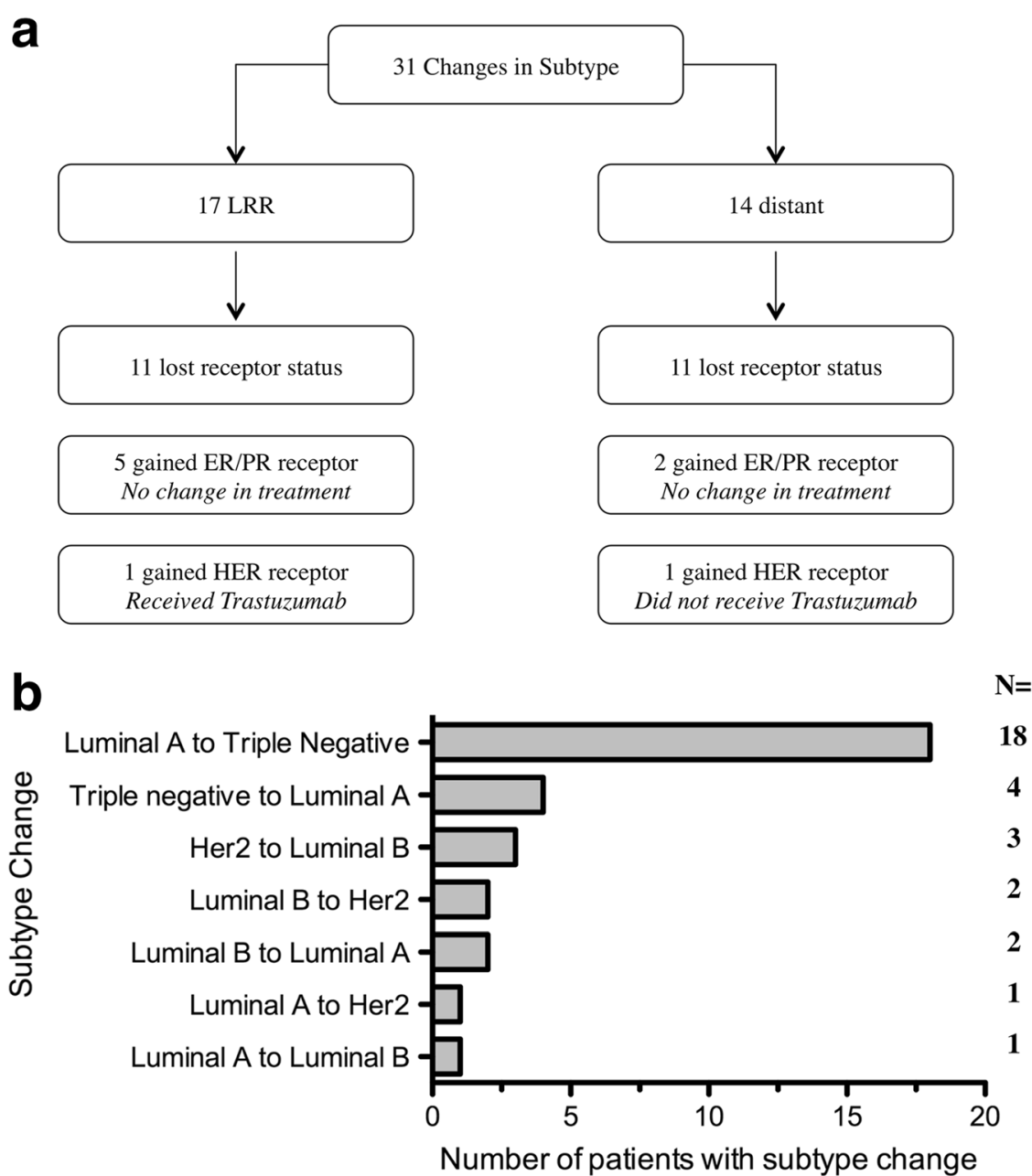

Fig. 1 Cohort description. a. Total number of discordant cases and impact on treatment changes. b. Specific changes in subtype from primary to recurrence 
$p<0.05$ ) (Fig. 2B). Comparing patients who changed from triple-negative to luminal A $(n=4)$ to the concordant triple negative group $(n=35)$, there was no significant difference in 10 year OS (35 vs. 49 months, $p=0.378$ ) or 5 year PRS (13.5 months vs. 14.2 months, $p=0.919$ ) (Additional file 2: Figure S1).

\section{Potential changes to treatment}

In terms of changes in subtype that could potentially lead to a change in treatment, nine patients (6.8\%) gained receptor status on recurrence. Seven patients went from HR negative to positive, with 6 patients going from ER negative to positive (ALLRED score 0 in the primary to $>2$ in the recurrence). One patient went from PR negative to positive. Of these seven patients, five had a loco-regional recurrence and two had distant recurrences (one liver, one lung). None of these patients received additional endocrine therapy following the biopsy results of the recurrence. All nine patients are deceased with a mean OS of 52 months and a mean PRS of 21 months.

Two patients gained HER2 receptor status, both going from HER2 score of 0 on Herceptest of the primary to 1 of the recurrence, with both subsequently testing
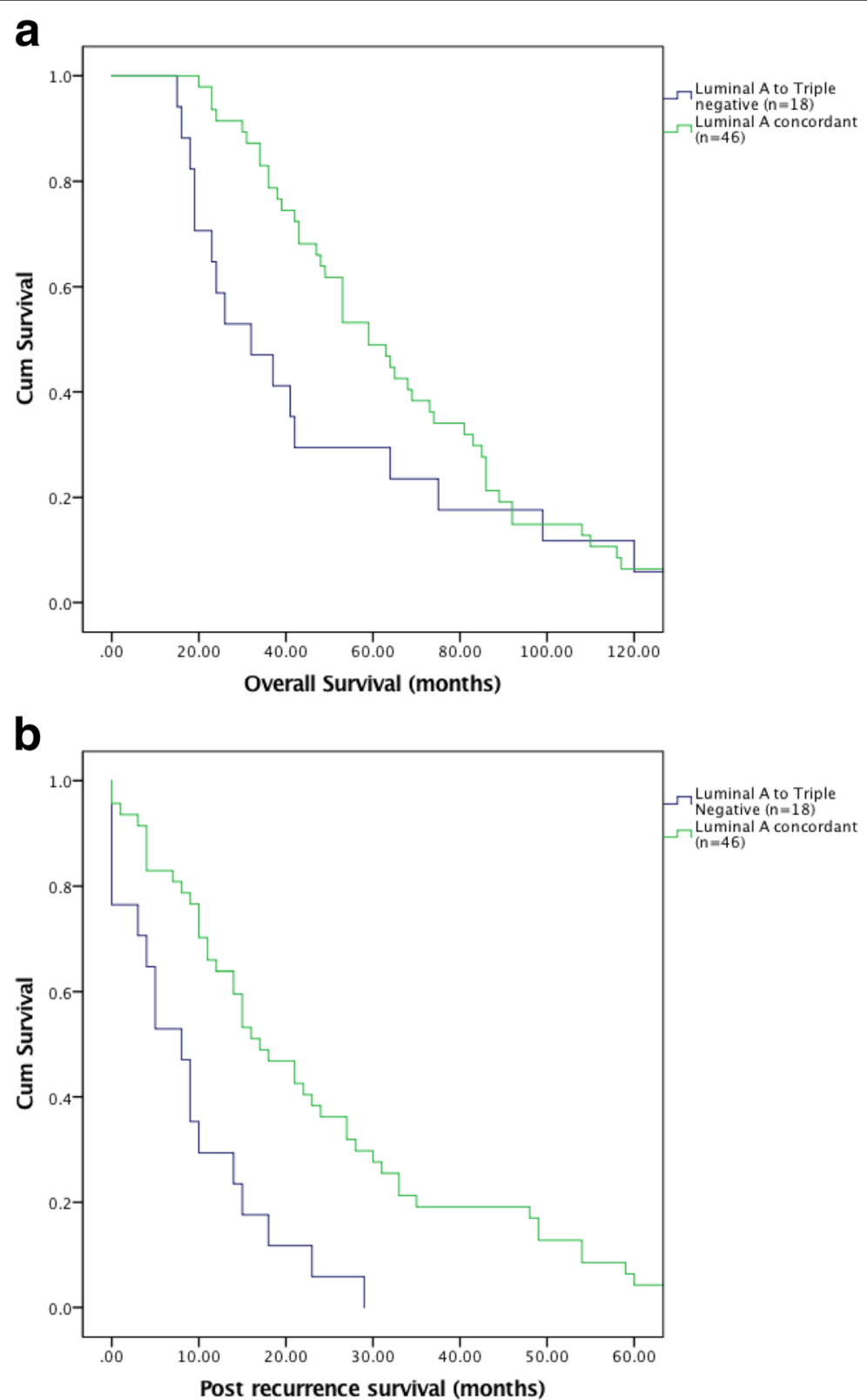

Fig. 2 Luminal (a) to triple negative $(n=18)$ vs. triple negative concordant $(n=46)$. A 10 year overall survival $(p=0.064)$. b 5 year post-recurrence survival $(p<0.05)$ 
positive on FISH. One patient had a distant recurrence in bone, and was enrolled in the TRIO 022 trial [14], subsequently receiving Letrozole, Denosumab and a CDK inhibitor without receiving Trastuzumab. This patient is alive with an OS of 145 months and a PRS of 33 months. The other patient had a loco-regional recurrence and subsequently received 1 year of Trastuzumab. This patient is alive with an OS of 179 months and a PRS of 96 months.

In summary, only one patient in our study of nine who gained receptor status ultimately received additional targeted therapy.

\section{Discussion}

In our single-centre analysis the rate of subtype change of was $23.5 \%$, supporting previously published figs. [15, 16]. In terms of the specific changes in subtype, the most frequent change was from luminal A to triple negative, and this group had a significantly poorer 5 year PRS. Despite initially diverging OS, ultimately both groups have similar 10 year OS. Other studies have demonstrated a similar reduced survival in patients who change form HR positive to negative on recurrence [16-20].

Single receptor discordance was $20.4 \%, 37.8 \%$, and $3 \%$ for ER, PR and HER2 receptor respectively, similar to that reported in a recent meta-analysis examining 48 papers, which reported pooled discordance rates of $20 \%$, $33 \%$ and $8 \%$ for ER, PR and HER2 receptor [6]. HER2 receptor exhibits the lowest rate of discordance between primary and recurrence [21]. Loss of single receptor status was more common than gain for $\operatorname{ER~}(p=0.04)$ and PR $(p=0.01)$, in line with published data [22].

There are a number of possible aetiologies for receptor discordance. Firstly, variability exists in the reproducibility and accuracy of immunohistochemical staining [23]. There is also variability in sampling methods, for example fine needle aspiration or core biopsy versus surgical extraction in the primary tumour and in sampling of the recurrence that can contribute to the discrepancy. With the advent of next generation sequencing technology, it has become apparent that breast cancer demonstrates both intra-tumour and inter-tumour heterogeneity to a greater extent than previously understood. The discordance in receptor status may demonstrate clonal genome evolution $[6,24,25]$ and the clone with the more aggressive phenotype could potentially initiate the micro-metastatic process [26]. Biological drift is another potential cause, for example selective eradication of ER/PR positive cells by hormonal therapy could leave behind a population of ER/PR negative cells that in time could metastasize [27]. Genuine switches in biology of the cancer appear to be a rare event based on currently available gene expression data $[28,29]$, however this does not exclude the potential for smaller scale genomic alterations and mutations [30]. Heterogeneity between patient's primary and recurrence may be due to newly acquired biological characteristics that allow tumour cells to travel via the circulatory/ lymphatic systems and to metastasize to new sites [31]. Change in receptor status may contribute to this increased capacity for invasion as endocrine and growth factor signalling pathways are implicated in invasion and metastasis [32, 33].

In terms of potential alterations to treatment and survival benefits of performing a recurrence biopsy, there is conflicting data with much of the literature being retrospective and examining small populations with variability in assay used, site of metastasis and definition of recurrence [7, 18, 34, 35]. Two prospective studies aimed to address these limitations - the BRITS study [36] in the United Kingdom which was carried out at 20 secondary care sites, and the DESTINY study [10] conducted at a single centre in Toronto, Canada. Both were conducted using similar eligibility and exclusion criteria. A pooled analysis of the two studies examined the proportion of patients who underwent a change in management based on the results of the recurrence biopsy [37]. 289 patients underwent biopsy of recurrence, consisting of $48 \%$ loco-regional recurrences and $52 \%$ distal metastases. $14.2 \%$ of patients had a change in management based on their results. However, on further analysis, half of the changes in treatment regime were due to loss of receptor status, new primary diagnosis or benign disease on biopsy. In total only $7.1 \%$ of patients had a treatment added due to gain in receptor status.

In terms of the effect that changing management had on patient outcomes, the results were unclear and only the DESTINY trial looked at overall survival. There was no significant association between overall survival and discordance (median OS 27.6 vs. 30.2 months in the concordant and discordant groups respectively). Other retrospective studies have identified a change in management plan in $12-20 \%$ of patients where there was a gain in receptor status $[15,35,38]$.

Current guidelines by the American Society of Clinical Oncology (ASCO) [39] advise offering biopsy where feasible to patients with recurrence for receptor status. Treatment should be guided preferentially by the ER/PR/HER2 status of the recurrence if justified by the clinical scenario and conforming to the patient's wishes. The panel's recommendations are deemed to be "moderate" due to the paucity of clinical evidence demonstrating that altering therapy based on receptor change has significant health outcomes. A number of barriers exist to routine biopsy of tumour recurrence it may not be technically feasible or safe to perform, there is a $2 \%$ risk of major complications [40], and the patient or physician may decide against it. 
Limitations of our study include the relatively small sample size. The retrospective nature of the study made it difficult to accurately collate data on patient's precise treatment regimes. Furthermore, as discussed above technical misclassification is a significant contributor to receptor discordance. Gain in receptor status may be attributable to this misclassification as opposed to a genuine change in tumour biology [41, 42]. It may be beneficial to carry out an independent re-review of the pathology slides from this study to identify what proportion of subtype change was due to this misclassification.

\section{Conclusions}

In summary, our study demonstrates the discordance of receptor and subtype between primary and recurrent breast cancer at our institution. It highlights the importance of performing a biopsy of recurrent breast cancer, due to the implications that change in subtype has on survival. Further research is required to investigate the aetiology and biology of subtype discordance and the optimal strategy for treatment change based on this discordance. Our results highlight the need for a prospective, multicentre trial collecting data on patients who experience recurrence (including routine biopsy's of recurrence), to establish if all recurrent patients should be biopsied, or only a subset of patients most likely to benefit from additional treatment options.

\section{Additional files}

\section{Additional file 1: Table S1. Impact of Location/Neoadjuvant} chemotherapy/Surgery on discordance. Quantifying: Recurrence location, Neoadjuvant Chemo Rx, Surgery, Change subtype, Gain of Receptor. (DOCX $24 \mathrm{~kb})$

Additional file 2: Figure S1. Triple negative to Luminal A $(n=4)$ vs. triple negative concordant $(n=35)$. A 10 year overall survival $(p=0.378)$. B 5 year post recurrence survival $(p=0.919$ ). (TIFF $542 \mathrm{~kb}$ )

\section{Abbreviations}

CDK: Cyclin dependent kinase; ER: Estrogen receptor; FISH: Fluorescence in situ hybridization; HER2: Her2 over-expressing breast cancer; Her2: Human epidermal growth factor receptor 2; HR: Hormone receptor; HR: Hormone receptor; IHC: Immunhistochemical; OS: Overall survival; PR: Progesterone receptor; PRS: Post-recurrence survival; TN: Triple Negative

\section{Acknowledgements}

The authors would like to thank the translational Breast Cancer research group for critical discussion of this manuscript.

\section{Funding}

This work is supported by funding from Breast Cancer Research. The funding body was not involved in the design of the study, collection, analysis, interpretation or writing of the manuscript.

\section{Availability of data and materials}

The datasets used and/or analysed during the current study are available from the corresponding author on reasonable request.

\section{Authors' contributions}

PFM, AM, AR, CC, CM, RM, BK collected and analysed the data. PFM, JALB, MK wrote the manuscript. JALB, MK final approval of the manuscript. All authors have read and approved the manuscript.

Ethics approval and consent to participate

This study was conducted in accordance with the granted National University of Ireland Galway and University College Hospital Galway ethical approval. All patients had histologically confirmed breast cancer and all relevant clinic-pathological and demographic data were obtained from a prospectively maintained breast cancer database.

\section{Consent for publication}

Not applicable.

\section{Competing interests}

The authors declare that they have no competing interests.

\section{Publisher's Note}

Springer Nature remains neutral with regard to jurisdictional claims in published maps and institutional affiliations.

\section{Author details}

${ }^{1}$ Discipline of Surgery, Lambe Institute for Translational Research, School of Medicine, National University of Ireland Galway, Galway, Ireland. ²Discipline of Surgery, Galway University Hospital, Galway, Ireland.

Received: 12 July 2017 Accepted: 5 February 2018

Published online: 20 February 2018

\section{References}

1. Ferlay J,SI, Ervik M, Dikshit R, Eser S, Mathers C, Rebelo M, Parkin DM, Forman D, Bray F. Cancer Incidence and Mortality Worldwide: IARC CancerBase No. 11 [Internet]. Lyon: International Agency for Research on Cancer; 2013.

2. Edge SB, Compton CC. The American joint committee on cancer: the 7th edition of the AJCC cancer staging manual and the future of TNM. Ann Surg Oncol. 2010;17(6):1471-4.

3. Network CGA. Comprehensive molecular portraits of human breast tumours. Nature. 2012;490(7418):61-70.

4. Sorlie T, et al. Gene expression patterns of breast carcinomas distinguish tumor subclasses with clinical implications. Proc Natl Acad Sci U S A. 2001, 98(19):10869-74.

5. Early Breast Cancer Trialists' Collaborative, G. Effects of chemotherapy and hormonal therapy for early breast cancer on recurrence and 15year survival: an overview of the randomised trials. Lancet. 2005; 365(9472):1687-717.

6. Aurilio $G$, et al. A meta-analysis of oestrogen receptor, progesterone receptor and human epidermal growth factor receptor 2 discordance between primary breast cancer and metastases. Eur J Cancer. 2014; 50(2):277-89.

7. Lindstrom LS, et al. Clinically used breast cancer markers such as estrogen receptor, progesterone receptor, and human epidermal growth factor receptor 2 are unstable throughout tumor progression. J Clin Oncol. 2012; 30(21):2601-8.

8. Liedtke C, et al. Prognostic impact of discordance between triple-receptor measurements in primary and recurrent breast cancer. Ann Oncol. 2009; 20(12):1953-8

9. Santinelli A, et al. HER-2 status discrepancy between primary breast cancer and metastatic sites. Impact on target therapy. Int J Cancer. 2008;122(5):999-1004.

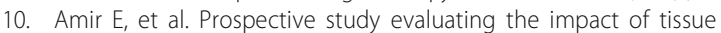
confirmation of metastatic disease in patients with breast cancer. J Clin Oncol. 2012;30(6):587-92.

11. Allred DC, et al. Prognostic and predictive factors in breast cancer by immunohistochemical analysis. Mod pathol off j U S Canadian Acad Pathol, Inc. 1998;11(2):155-68.

12. Jacobs TW, et al. Specificity of HercepTest in determining HER-2/neu status of breast cancers using the United States Food and Drug Administrationapproved scoring system. J Clin Oncol. 1999;17(7):1983. 
13. Owens MA, Horten BC, Da Silva MM. HER2 amplification ratios by fluorescence in situ hybridization and correlation with immunohistochemistry in a cohort of 6556 breast cancer tissues. Clin Breast Cancer. 2004;5(1):63-9.

14. Wolff AC. CDK4 and CDK6 inhibition in breast cancer - a new standard. N Engl J Med. 2016;375(20):1993-4.

15. St Romain $\mathrm{P}$, et al. Organotropism and prognostic marker discordance in distant metastases of breast carcinoma: fact or fiction? A clinicopathologic analysis. Hum Pathol. 2012;43(3):398-404.

16. Dieci MV, et al. Discordance in receptor status between primary and recurrent breast cancer has a prognostic impact: a single-institution analysis. Ann Oncol. 2013;24(1):101-8.

17. Shiino $\mathrm{S}$, et al. Prognostic impact of discordance in hormone receptor status between primary and recurrent sites in patients with recurrent breast cancer. Clin Breast Cancer. 2016;16(4):e133-40.

18. Hoefnagel LD, et al. Receptor conversion in distant breast cancer metastases. Breast Cancer Res. 2010;12(5):R75.

19. Kimbung $S$, et al. Contrasting breast cancer molecular subtypes across serial tumor progression stages: biological and prognostic implications. Oncotarget. 2015;6(32):33306-18.

20. Hoefnagel LDC, et al. Discordance in ERa, PR and HER2 receptor status across different distant breast cancer metastases within the same patient. Ann Oncol. 2013;24(12):3017-23.

21. Chan $\mathrm{A}$, et al. A retrospective study investigating the rate of HER2 discordance between primary breast carcinoma and locoregional or metastatic disease. BMC Cancer. 2012;12(1):555

22. Yeung $C$, et al. Estrogen, progesterone, and HER2/neu receptor discordance between primary and metastatic breast tumours-a review. Cancer Metastasis Rev. 2016;35(3):427-37.

23. Allred DC. Commentary: hormone receptor testing in breast cancer: a distress signal from Canada. Oncologist. 2008;13(11):1134-6.

24. Shipitsin $\mathrm{M}$, et al. Molecular definition of breast tumor heterogeneity. Cancer Cell. 2007;11(3):259-73.

25. Navin N, et al. Tumour evolution inferred by single-cell sequencing. Nature. 2011:472(7341):90-4.

26. Pertschuk LP, et al. Marked Intratumoral heterogeneity of the protooncogene her-2/neu determined by three different detection systems. Breast J. 1999;5(6):369-74.

27. Kurbel S. Selective reduction of estrogen receptor (ER) positive breast cancer occurrence by estrogen receptor modulators supports etiological distinction between ER positive and ER negative breast cancers. Med Hypotheses. 2005;64(6):1182-7.

28. Lacroix M, Toillon RA, Leclercq G. Stable 'portrait' of breast tumors during progression: data from biology, pathology and genetics. Endocr Relat Cancer. 2004;11(3):497-522

29. Bernards R, Weinberg RA. A progression puzzle. Nature. 2002;418(6900):823.

30. Shah SP, et al. Mutational evolution in a lobular breast tumour profiled at single nucleotide resolution. Nature. 2009;461(7265):809-13.

31. Chambers AF, et al. Molecular biology of breast cancer metastasis. Clinical implications of experimental studies on metastatic inefficiency. Breast Cancer Res. 2000;2(6):400-7.

32. Maynadier $\mathrm{M}$, et al. Role of estrogens and their receptors in adhesion and invasiveness of breast cancer cells. Adv Exp Med Biol. 2008;617:485-91.

33. Huang $\mathrm{TH}$, et al. Up-regulation of miR-21 by HER2/neu signaling promotes cell invasion. J Biol Chem. 2009;284(27):18515-24.

34. Gong Y, et al. Stability of estrogen receptor status in breast carcinoma: comparison between primary and metastatic tumors with regard to disease course and intervening systemic therapy. Cancer. 2011;117(4):705-13.

35. Zidan J, et al. Comparison of HER-2 overexpression in primary breast cancer and metastatic sites and its effect on biological targeting therapy of metastatic disease. Br J Cancer. 2005;93(5):552-6.

36. Thompson AM, et al. Prospective comparison of switches in biomarker status between primary and recurrent breast cancer: the breast recurrence in tissues study (BRITS). Breast Cancer Res. 2010;12(6):R92.

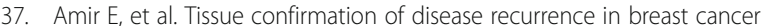
patients: pooled analysis of multi-centre, multi-disciplinary prospective studies. Cancer Treat Rev. 2012;38(6):708-14.

38. Simmons $C$, et al. Does confirmatory tumor biopsy alter the management of breast cancer patients with distant metastases? Ann Oncol. 2009:20(9):1499-504.

39. Van Poznak C, et al. Use of biomarkers to guide decisions on systemic therapy for women with metastatic breast cancer: American Society of Clinical Oncology clinical practice guideline. J Clin Oncol. 2015;33(24):2695-704.
40. Gupta S, et al. Quality improvement guidelines for percutaneous needle biopsy. J Vasc Interv Radiol. 2010;21(7):969-75.

41. Allott EH, et al. Intratumoral heterogeneity as a source of discordance in breast cancer biomarker classification. Breast Cancer Res. 2016;18(1):68.

42. Davidson NE. "Take two"? The role of second opinions for breast biopsy specimens. BMJ. 2016;353:13256.

\section{Submit your next manuscript to BioMed Central and we will help you at every step:}

- We accept pre-submission inquiries

- Our selector tool helps you to find the most relevant journal

- We provide round the clock customer support

- Convenient online submission

- Thorough peer review

- Inclusion in PubMed and all major indexing services

- Maximum visibility for your research

Submit your manuscript at www.biomedcentral.com/submit

) Biomed Central 